\title{
REFLEXÕES SOBRE O PAPEL DA CULTURA NA CIDADE DE SÃO PAULO
}

\author{
Danilo Santos de Miranda \\ Sociólogo e Filósofo, Diretor Regional do Sesc-SP
}

\begin{abstract}
Resumo: Em poucas décadas, as grandes cidades de países em desenvolvimento tiveram uma seqüência de transformações tão brutais que é possível afirmar que várias vezes foram construídas, demolidas e reconstruídas; bairros se deterioraram e refloresceram; cidades nasceram dentro de cidades ou se colaram nos limites da periferia; grandes avenidas foram rasgadas no tecido urbano já solidificado. Junto com esse terremoto urbano, uma cultura metropolitana se desenvolveu, apressada pela globalização, com contornos incivilizados, baseada em auto-soluções para a sobrevivência, o que gerou criatividade e solidariedade, mas também o narcotráfico, a violência, a criminalidade e relações sociais apartadas. Neste contexto, ganha força a necessidade de uma política cultural para São Paulo fundada no multiculturalismo e em novas formas de sociabilidade.

Palavras-chave: desenvolvimento urbano; cultura metropolitana; política cultural.
\end{abstract}

$\mathrm{E}$ ste texto, como expressa seu título, antes de se constituir em trabalho de investigação realizado nos modelos propostos pelo método científico, propõe-se contribuir para os estudos urbanos com reflexões e idéias que nasceram de leituras e de contatos pessoais com pesquisadores e administradores de políticas públicas, com produtores culturais e artistas e com o público de eventos culturais em geral.

A vida sociocultural de uma metrópole com as dimensões de São Paulo envolve tamanha quantidade de questões, que se constitui tarefa para muitos especialistas, exigindo estudos multi e interdisciplinares. As questões macroeconômicas e sociais colocadas pela globalização, como viagem tecnológica do capital rumo a sítios de maior lucratividade, forças de conformação ou resistência ao domínio mundial do capital financeiro e da tecnologia, fluxo de capital e de investimentos econômicos entre regiões de uma mesma cidade, desigualdades econômicas, emprego e estratégias de sobrevivência da população mais pobre desalojada e apartada da qualidade de vida proposta pela visão de modernidade urbana, possibilidades de participação democrática no planejamento urbano, na gestão e nos usos da cidade, questões de proporcionalidade entre espaços de domínio público e privado, formação ou manutenção de identidades pessoais, de grupos e etnias possibilitadas pelo cosmopolitismo, condições para o advento de cidades mundiais receptivas a todo tipo de cidadão e suas culturas, são abordadas por inúmeros pesquisadores nos dias de hoje em suas tentativas de compreenderem a dinâmica econômica, social e cultural que pulsa na vida nas grandes metrópoles.

Todos esses fatores e muitos outros concorrem para a formação de uma cultura metropolitana, que se modela por auto-soluções, porque os serviços públicos e institucionais chegam muito tempo depois da urbanização. O planejamento urbano, seja de que tipo for, não alcança os grandes contingentes populacionais da periferia e de bairros deteriorados, dando margem ao surgimento de socializações autônomas e segregadas, onde a ausência da administração pública cria a justiça pelas próprias mãos, a segurança privada, as invasões, a sobrevivência baseada na economia da droga e em atividades ilegais, a troca de favores, a corrupção, a ignorância, o misticismo e manifestações culturais que saltam diretamente da cultura de raiz para a cultura televisiva e importada.

\section{METRÓPOLE INDUSTRIAL - A GRANDE ATRAÇão}

A partir dos anos 50, a instalação de indústrias de base na Região Metropolitana de São Paulo trouxe, para a capital paulista, um contingente imenso de trabalhadores, acarretando um crescimento maior do que esta poderia 
suportar em espaço de tempo tão curto, criando condições espaciais ainda hoje fortemente presentes em seu funcionamento.

Muitos dados, em vários períodos, mostram que o paulistano é basicamente um imigrante. Ainda hoje, 55\% de seus habitantes com mais de 15 anos nasceram em outras localidades. Este percentual, que já foi maior, ainda é bastante significativo e só diminuirá com a substituição de gerações, a emigração e a diminuição do ritmo do crescimento populacional.

O singular crescimento da capital paulista é um fenômeno conhecido: localizada num planalto, próximo da Serra do Mar e do Porto de Santos, São Paulo aos poucos concentrou a exportação regional e a importação de mercadorias em diversos ciclos da economia, acumulando o capital necessário para a industrialização e atraindo grandes contingentes de população à procura de trabalho e dos serviços públicos. No início dos grandes fluxos migratórios, a partir da Segunda Guerra Mundial até o fim da década de 70, os objetivos do trabalho no grande centro industrial que se erguia eram o aumento da capacidade de consumo de mercadorias essenciais e alguns bens de conforto - como o rádio, a geladeira, o televisor e, mais tarde, o carro -, bem como a inclusão do trabalhador e familiares no sistema público de saúde, previdência e educação. No entanto, a urbanização sem cidade acompanhou o processo de expansão industrial com tamanha rapidez que criou uma organização caótica, com as moradias sendo jogadas em grande quantidade para a periferia, em espaços precários e sem infra-estrutura. Prevaleceu em São Paulo uma expansão permanente, sem qualidade, com constantes transgressões às leis.

Desenraizado e afastado do círculo de suas relações sociais, o migrante de São Paulo foi levado a criar um estilo de vida determinado pelas condições de sobrevivência que foi obrigado a enfrentar. Vivendo em habitações mais baratas e, por isso, acanhadas, inacabadas, distantes do local de trabalho e usadas apenas como dormitório, enfrentando longas horas de percurso em trânsito caótico, realizando grandes cargas de horas extras no trabalho, alimentando-se inadequadamente, sendo obrigado a se afastar das relações de vizinhança e parentesco, apressando o ritmo da vida e fugindo do contexto urbano no tempo livre, o paulistano criou um estilo de vida sacrificado, baseado no trabalho e fundado na ética da responsabilidade, do compromisso e da renúncia. Os refrões criados no passado sobre a cidade e seus habitantes - "aqui se trabalha", "São Paulo não pode parar", "o paulistano é sério e não sabe se divertir", "está sempre com pressa", "respira fumaça", "enfrenta congestionamento até em feriado", "mora dependurado" - apenas servem para testemunhar alguns itens de qualidade de vida, estima da cidade, auto-estima e cidadania que foram relegados a um segundo plano, numa troca pelo emprego, determinada pelas condições históricas do desenvolvimento que aqui se efetivou.

Porém, será que este relacionamento desenraizado e meio "forasteiro" do paulistano com a cidade permanece ainda hoje? Parece que sim. Em pesquisa realizada em 1995, pelo Serviço Social do Comércio e pela Fundação Escola de Sociologia e Política, verificou-se que $71 \%$ das pessoas com alguma ocupação que viajaram de férias foram para a casa de parentes e, em feriados prolongados, a metade dos habitantes da capital foge para outras localidades. No entanto, um dado da mesma pesquisa pode ser revelador de mudança de atitude: $41 \%$ dos paulistanos estão insatisfeitos com seu lazer, enquanto apenas $14 \%$ não estão satisfeitos com o tipo de trabalho que executam, quando este último item sempre se constituiu no principal foco de insatisfação nas pesquisas realizadas em todo o mundo. Aparentemente, o paulistano agora considera o lazer um aspecto importante de seu cotidiano, diferentemente da cultura de trabalho e privações dos primórdios da explosão urbana de São Paulo. Parece haver uma expectativa de melhoria numa dimensão da existência que antes dava lugar a outros objetivos. Novos objetos de desejo, novos signos e imagens - portanto, uma nova simbologia - podem estar produzindo as novas relações dos habitantes com o espaço de seu cotidiano.

\section{A ERA DOS SERVIÇOS E DA INFORMAÇÃO - UM TEMPO PARA O REPLANEJAMENTO}

Após o período áureo de atração da grande indústria, entre as décadas de 60 e 80, algumas mudanças econômicas, sociais e de ocupação do espaço urbano começaram a ocorrer em São Paulo nos anos 90 e são apontadas por vários estudos. A taxa de natalidade decresceu tanto na capital paulista como em seu contexto brasileiro, as migrações nacionais rumo a São Paulo diminuíram e a intensidade de êxodo da cidade aumentou. Apesar desses fenômenos combinados, a população continuou e continua em crescimento a curto e médio prazos, mas a taxas bem menores do que há duas ou três décadas. Mesmo com um incremento populacional menos intenso continuando a pressionar o espaço urbano pela demanda de moradia e 
circulação num processo desordenado de ocupação, já que os poderes públicos não terão a curto prazo os meios de se antecipar ao acúmulo das necessidades, é possível prever que as novas gerações de paulistanos, ao construírem seus projetos de vida integrados com a cidade, possam organizar e administrar o espaço de tal modo a terem acesso a um conjunto de bens simbólicos e intangíveis que qualificam a existência, como a cultura, o lazer e a convivência.

Na década de 90, São Paulo mergulhou rapidamente na era pós-industrial, caracterizada pelas tecnologias da informação, automação da indústria e sua dispersão territorial e predomínio dos serviços. Os indícios da nova era já são bastante visíveis na saída, do município, das indústrias de "segunda onda" - a fábrica e suas vilas operárias -, com o abandono de prédios e a transformação do perfil físico da cidade.

As metrópoles mundiais tendem a expulsar a grande indústria devido ao custo de instalações e operações, nível de remuneração da mão-de-obra, insegurança patrimonial e pessoal e legislações restritivas. Pelas facilidades de comunicação e transporte, elas podem ocupar sítios localizados em cidades mais convenientes e de menor custo operacional. No entanto, o corpo de administradores, a estrutura das telecomunicações, os centros financeiros, as bolsas de valores e outras atividades de caráter internacional permanecerão na metrópole, necessitando cada vez mais de atividades de cultura e lazer como apoio aos negócios.

Esse fenômeno da desindustrialização dos sítios urbanos metropolizados como o de São Paulo, decorrente do uso cada vez mais intensivo da eletrônica e, portanto, da informática e automação, poderá desconcentrar a moradia, o trabalho, a circulação e o lazer, criando menor necessidade de deslocamentos, melhorando o trânsito, diminuindo a poluição e permitindo novos usos para as localidades de forte transformação.

Evidentemente, nem todo tipo de produção industrial deverá se afastar da metrópole. É possível até mesmo um novo surto industrial, baseado em processos industriais limpos, empresas de pequeno e médio portes, na área de informática, comunicações e mídia. Estes setores juntos somam hoje quase metade do produto mundial.

A indústria do entretenimento, em São Paulo ainda restrita a espetáculos de massa, parques temáticos, produtos culturais desenvolvidos pelas diferentes mídias no domínio da imagem-som-texto e Internet, cresce rapidamente como em toda a rede mundial de metrópoles e promove a circulação de enormes somas de capital, aumentando o consumo e trazendo novas perspectivas de emprego.

O chamado Terceiro Setor, caracterizado por uma grande quantidade de organizações de pequeno e médio portes que atuam em serviços de cunho social, em setores como a educação, subsistência, tecnologia, meio ambiente, lazer e cultura, tende a crescer porque abandonou o sistema de tutela dos cidadãos mais carentes, adotando estratégias de inclusão de seus públicos-alvo na produção e no consumo alcançados pelos demais setores da sociedade.

Em todas as sociedades, na era pós-industrial, a força de trabalho estará cada vez mais centrada na criação e invenção e no conhecimento técnico-teórico. As melhores oportunidades de trabalho e a maior quantidade de vagas serão preenchidas por inventores e criadores, gestores de métodos e processos e por técnicos em geral. Assim, as áreas que mais deverão crescer nos próximos anos são o turismo de negócios e hospitalidade, os serviços de saúde, a pesquisa científica, a educação de ensino superior, a informática e sistemas de informação e a área de lazer, cultura e espetáculos.

Será o advento da sociedade da informação, e São Paulo terá uma nítida vocação para a área de serviços de toda natureza. Esta passagem é e continuará sendo traumática pela perda do emprego formal, mas poderá aumentar as possibilidades de ocupação no trabalho autônomo, temporário e de tempo parcial, em funções com ou sem a necessidade de especialização.

No final dos anos 90, São Paulo poderia ser considerada "cidade mundial", como facilmente são reconhecidas cidades como Nova York, Londres, Tóquio, Paris e outras? As limitações são muitas. São Paulo é síntese da problemática socioeconômica brasileira e, até certo ponto, mundial. Por muito tempo, continuará sendo uma metrópole de conflitos e contradições, de pobreza e de baixa qualidade de vida, de violência e segregação e de privatização do espaço público.

No entanto, a importância regional e mundial da metrópole paulistana já é um fato, porque é sede e pólo das grandes organizações transnacionais e se constitui em lugar de operações da economia globalizada, centralizando fluxos importantes das finanças e das telecomunicações. Tal importância adquirida nos negócios mundiais poderá obrigar a cidade a se transformar na direção de uma melhoria geral da infra-estrutura urbana como meio de competir pelos negócios e investimentos internacionais. 


\section{UMA POLÍTICA CULTURAL PARA SÃO PAULO NA ERA DOS SERVIÇOS E DA GLOBALIZAÇÃO}

\section{Fundamentos}

O espaço urbano é cada vez mais o espaço da cultura, o lugar onde florescem, desabrocham e fermentam as idéias contemporâneas, os valores de modernidade, a inovação e a criação, porque a cidade congrega, une e reúne, influencia, multiplica, combina e potencializa as várias sensibilidades e talentos. Por estes aspectos, nem mesmo a dispersão da indústria será capaz de dissipar a aglomeração urbana, como sinalizam as várias utopias de uma volta à vida rústica em contato com a natureza, fundamentada no desenvolvimento da teleinformação.

No entanto, como produção da alma humana, a cultura, no meio urbano das grandes metrópoles de países em desenvolvimento - caótico, deteriorado, excludente -, tenderá a produzir uma sensibilidade anárquica, que reflete todos os anseios do homem em todas as direções, em conflito ou harmonia aleatórios com as relações sociais circundantes. Uma cidade que oferece o caos e negligencia a necessidade de bem-estar geral da pessoa humana faz com que ela busque seu bem-estar na sombra dos arranha-céus e nos espaços deteriorados. A barbárie atual, apressada pela globalização, é a exacerbação daqueles aspectos do homem com que a cidade não fala, aquela parte de nós que não encontrou abrigo no meio urbano.

São Paulo, mais do que qualquer outra cidade, necessita de uma política de lazer e de cultura, para dar significação ao espaço urbano da vida cotidiana de seus habitantes, aumentando as dimensões existenciais de suas relações com a cidade para além da vida de trabalho e subsistência.

No entanto, essa política cultural necessariamente deve estar vinculada a um planejamento urbano que associe os interesses dos cidadãos e grupos sociais à gestão pública da cidade, às instituições de caráter público e ao empreendimento privado.

No mais das vezes, o que se tem visto são conceitos de planejamento urbano constituídos de intervenções em que a idéia e o plano prescindem da realidade, traduzindo idéias preconcebidas de como as cidades deveriam funcionar ou como elas deveriam ser. Para serem mais orgânicos, os planos precisam partir da realidade física, social e cultural preexistente, levando em conta os interesses de todos os atores sociais que intervêm na realidade e evitando se pautarem apenas pela estética e transposição de modelos.
Em metrópoles das dimensões de São Paulo, a especialização de funções para o conjunto da cidade não é possível numa era dos serviços e da informação. Para bairros e lugares específicos, o planejamento urbano deve sempre buscar a conquista ou a manutenção da diversidade de funções, ou uma combinação de funções especializadas.

As cidades sempre tiveram um papel de destaque em todas as civilizações: Atenas, Roma, Florença, Paris, Londres, Berlim, Nova York foram síntese do modo de vida no qual estavam inseridas, representando épocas de conquistas nas ciências, na filosofia e nas artes e, ao mesmo tempo, se convertendo em pólos irradiadores que impulsionaram as transformações, a inovação e a criação política, social, econômica e espiritual.

Hoje as metrópoles são cidades mundiais e sintetizam seus países e, mais remotamente, outras civilizações do mundo. Em sua estrutura localizam-se a arte, a filosofia e a ciência; os costumes, as tradições e a memória; os sistemas políticos e o direito; a administração financeira e a gestão dos negócios. Porém, este papel de liderança não está imune às contradições e conflitos do país, da região, do hemisfério e do planeta.

A recuperação desse papel civilizatório, para cidades caóticas, que cresceram às pressas, excluindo as necessidades e interesses da maioria, está num planejamento que possibilite a coexistência da ordem da vida comunitária com a desordem da sensibilidade e da criação, do coletivo com o individual, do racional com o mítico, do real com o imaginário, da dedicação com o prazer, do trabalho com o lazer, do técnico com o simbólico, do espaço aberto com o fechado, do público com o privado.

\section{Ações Culturais Emblemáticas}

Nos novos tempos da substituição da indústria pesada pela indústria da informática e pelos serviços, algumas ações são adequadas, coerentes e até necessárias para o impulso rumo a uma nova cultura metropolitana em São Paulo. Neste ponto não há como se esperar que o espontaneísmo dos criadores de cultura implementem, de maneira autônoma, essas mudanças culturais: é necessário um conjunto de ações coordenadas para adequar e melhorar a produção e os usos do espaço urbano. Deve-se colocar à disposição dos cidadãos um conjunto de serviços culturais, organizados segundo as novas necessidades do homem na era da informação, da sociedade pós-industrial e pós-moderna. Estamos, pois, no plano da gestão urbana, 
que deve garantir formas de participação as mais democráticas possíveis, com a inclusão de todos os agentes sociais implicados, cada um conforme o âmbito e extensão de sua ação.

Evidentemente, seria desejável que, antes de se pensar em reordenar o espaço urbano de acordo com novos critérios, todo cidadão tivesse garantidas sua subsistência e sua moradia e, então, poder-se-ia ter uma cidade com menos pobreza e menos violência e com maiores níveis de desenvolvimento sociocultural e maior qualidade de vida. Todavia, hoje, tanto os teóricos da pós-modernidade como o próprio habitante dos grandes centros urbanos tendem a enxergar a cidade como uma colagem, um mosaico composto de espaços, conteúdos culturais e comportamentos heterogêneos. Portanto, estratégias de intervenção pontuais, mais pluralistas e orgânicas, que optam pela mistura, diferenciação e descontinuidade também podem ter sentido simbólico para os habitantes e usuários e servir de impulso para o desenvolvimento sociocultural das comunidades.

Nesta mesma linha de intervenções pontuais, o tratamento das questões culturais para a cidade de São Paulo poderia preceder os macroplanos de replanejamento urbano e ter a função de transformar o meio urbano em espaço de vivência, melhorando o imaginário, a auto-estima, as próprias relações sociais e a cidadania.

Três estratégias de ação, todas já de algum modo iniciadas, têm alto potencial transformador, são emblemáticas e capazes de religar o habitante a São Paulo, dotar os espaços urbanos de significados para uma comunicação intersubjetiva e, à maneira de um mosaico, constituir uma coletividade paulistana.

O Centro - é o palco e cenário de representação de todos os cidadãos, pela história que ali se desenvolveu, pela concentração dos bens públicos e pelo exercício da cidadania através dos poderes constituídos. Em todas as culturas, sejam antigas ou modernas, a centralidade tem significados de união, congraçamento e convergência; é o lugar de comunicação à sociedade, de visibilidade, de reconhecimento, de encontro com o passado e com o presente. Nele o indivíduo vê e é visto, perde o anonimato mesmo estando com a multidão, porque age, presencia e participa dos muitos acontecimentos que se desenrolam na paisagem urbana.

Uma revitalização do Centro é estratégica, porque é o lugar de mais alta densidade da presença de infra-estrutura e investimentos já realizados e porque é o espaço urba- no onde todo o visitante gostaria de estar. Esta importância cresce numa era de serviços e turismo de negócios globalizados.

A recuperação do Centro deve ser realizada com pressupostos democráticos, sem expulsões, com a participação de todos os grupos de interesses, para se conseguir transformá-lo em espaço multifuncional, com muitas especializações, destinado a compras, turismo, cultura, convenções e moradias, com uso e freqüência 24 horas por dia, com prevalência do público sobre o privado nos espaços abertos e de circulação. Por ser o ponto de convergência das relações simbólicas do habitante com sua cidade, o Centro deve ser recuperado, embelezado e cuidado de tal modo a servir de estímulo à convivência e ao respeito com a diversidade cultural e de estímulo à irradiação de comportamentos até mesmo para dentro dos espaços privados. A programação cultural que vier a ser desenvolvida nos vários logradouros públicos recuperados terá que necessariamente facilitar o acesso dos cidadãos de todas as camadas sociais e regiões, evitando-se a elitização. Deste ponto de vista, a multifuncionalidade, se também apoiada na iniciativa privada, com a intermediação do poder público, já será capaz de promover a diversidade de interesses.

O Rio Tietê - foi, durante muito tempo, uma das formas negativas que os novos habitantes de São Paulo tinham de relatar e contar aos parentes e vizinhos deixados para trás as suas dificuldades de adaptação ao meio urbano industrial hostil, já que a maioria dos moradores era do interior do Brasil, onde a paisagem natural constituía-se no elemento estético de maior presença em seu cotidiano. A despoluição e o paisagismo às margens dos rios Tietê $\mathrm{e}$ Pinheiros, além de proporcionar um lazer natural e descanso na paisagem urbana de concreto e asfalto, representaria o estabelecimento de uma nova relação dos habitantes com a cidade na era de prevalência da imagem. A função estratégica da recuperação do Tietê e do Pinheiros caracteriza o simbolismo de substituição da era da indústria poluidora pela nova era de uma produção mais limpa, o que poderia também contribuir para a substituição dos modelos culturais de relacionamento com a cidade.

O Reaproveitamento de Complexos Construtivos - seja porque estes estão desativados pela fuga das indústrias, seja porque sediaram atividades que sofreram profundas modificações, é uma estratégia de reurbanização mais diretamente relacionada com uma política cultural, enten- 
dida como um conjunto de serviços culturais organizados segundo agentes intermediadores e colocados à disposição dos cidadãos.

A lógica econômica, em geral, se pauta pela cultura da substituição de construções, renovando o perfil da cidade. Porém, em muitos casos, os grandes complexos fabris, galpões de depósito e oficinas podem ser reutilizados e adaptados para outros usos. O valor econômico dessa mudança para a sociedade pode estar na abertura de vagas para o emprego, já que muitos serviços exigem atendimento pessoal e têm grande diversidade.

Os tipos de uso que se podem fazer desses espaços devem estar adequados à era dos serviços e da informação, como os serviços públicos e comunitários, serviços da educação formal, reprofissionalização e cursos de desenvolvimento pessoal, centros de desenvolvimento da pesquisa e de criação e, principalmente, centros de lazer cultural. Em todos esses casos, é conveniente o uso intenso das tecnologias de informação disponíveis, uma vez que hoje sua presença constitui-se em fator educativo e de estímulo à aprendizagem.

A multiculturalidade como critério de qualidade das atividades culturais é extremamente adequada para São Paulo. Em primeiro lugar, o pluralismo é adequado à realidade da formação da cidade, fruto das migrações intensas de estrangeiros e de brasileiros vindos das mais diversas regiões que se constituem em elemento de ligação desse migrante com a cidade, e à criação de uma vida sociocultural própria, substituindo sobrevivência por existência. Em segundo lugar, é adequada para a metrópole terciária, em que predomina a visão pós-moderna de colagem de recortes culturais diferenciados e a desconstrução de hierarquias arraigadas em que predominam preconceitos culturais.

Entretanto, uma política cultural de disseminação de ocupação de espaços adaptados para a vivência cultural tem um sentido civilizatório no contexto das mudanças sociais, econômicas e culturais da sociedade pós-industrial. O uso intensivo de tecnologias da informação, apesar de indicar que o homem moderno poderá até aumen- tar sua comunicação com seus semelhantes, conectado pela telecomunicação, provocará necessariamente uma residencialização da vida cultural e uma diminuição dos contatos face-a-face. Neste contexto, os espaços culturais multifuncionais, com atividades diversificadas e democratizadas, poderão constituir-se na função urbana capaz de evitar a nova barbárie representada pelo domínio da ciência e da tecnologia, pelo excesso da informação impessoal e pelo consumo, porque a cultura é o campo da sociabilidade face-a-face, da criatividade, das emoções, da invenção e do imaginário. Várias experiências mostram que a arte, a sociabilidade, o esporte e as atividades comunitárias em geral têm importante papel na recuperação da auto-estima e da identidade dos cidadãos e, por isso, atuam como elementos de reorganização do espaço urbano, substituindo comportamentos culturais segregados e baseados em autosoluções por comportamentos de civilidade, tolerância, convivência e cooperação.

\section{REFERÊNCIAS BIBLIOGRÁFICAS}

BRISSAC, N. (org.). Zona Leste de São Paulo - Pesquisa ArteCidade/Sesc. São Paulo, edição provisória, 1999-2000.

BURKE, P. "Cidades e criatividade”. Folha de S.Paulo. São Paulo, Caderno Mais!, $19 / 11 / 2000$.

CASTELlS, M. A Era da Informação. São Paulo, v. I, II e III, Paz e Terra, 1999. FRUGOLI JUNIOR, H. Centralidade em São Paulo. São Paulo, Cortez Ed., 2000. GOLDBERG, D.T. (org.). Multiculturalism: a critical reader. Malden, USA e Oxford, UK, 1994. Blackwell Publishers Ltd.

HILlMAN, J. Cidade e alma. São Paulo, Studio Nobel, 1993.

IANNI, O. "Metrópole e globalização". In: SOUZA, M.A.A. et alii (orgs.). Metrópole e globalização. São Paulo, Ed. Cedesp, 1999.

JACOBS, J. Morte e vida de grandes cidades. São Paulo, Martins Fontes, 2000. MEYER, R. "São Paulo anos 90”. Jornal da USP. São Paulo, USP, 2-8/10/2000.

MIRANDA, D.S. de. "Metropolização e globalização". In: SOUZA, M.A.A. et alii (orgs.). Metrópole e globalização. São Paulo, Ed. Cedesp, 1999.

MORIN, E. "Uma educação adaptada à sociedade globalizada". Jornal da Tarde. São Paulo, Caderno Sábado, 22/07/2000.

REIS FILHO, N.G. São Paulo e outras cidades. São Paulo, Hucitec, 1994.

ROGERS, R. Ciudades para un pequeño planeta. Barcelona, Editorial Gustavo Gili, 2000.

SASSEN, S. "A cidade e a indústria global do entretenimento". In: Lazer numa sociedade globalizada. São Paulo, Sesc, 2000. 